\section{A MERE APPENDIX}

Sherlock Holmes famously described himself in a way that resonates with A Fo Ben "I am a brain, Watson. The rest of me is a mere appendix." So spare a thought for this lowly vestigial organ. In two independent datasets, involving a staggering 1.6 million people (91 million person years), the authors identified that prior appendectomy was associated with a lower risk for Parkinson's disease. Interestingly, this was particularly so for people living in rural areas. Why might this be? The authors show that even in health the human appendix contains intraneuronal $\alpha$-synuclein aggregates and an abundance of Parkinson's disease pathology-associated $\alpha$-synuclein truncation products.

Sci Transl Med. 2018;10:465.

\section{TAURUS, GEMINI OR CANCER?}

In investigating someone with a cryptic multisystem illness, it would be beneficial to have a bloodhound that could effectively screen for sickness. Well, a recent paper identifies an 'ESR' for cancer-a quick and easy screening test that exploits key methylation features of cancer genomics.
The epigenetic reprogramming of cancer creates a distinct methylation landscape that includes clustered methylation at regulatory regions separated by large intergenic tracks of hypomethylated regions. The test uses a colourchanging fluid to reveal the presence of malignant cells anywhere in the body and provides results in less than 10 minutes. Despite the science being complex the implementation appears reassuringly simple.

Nat Commun. 2018;9 (1):4915.

\section{ARRESTED DEVELOPMENT}

What are the real-world consequences of the Zika epidemic? A total of 182 children exposed to Zika in utero were followed prospectively and 94 children underwent both neuropsychology and neuroimaging assessments. Ten children (11\%) had structural abnormalities visible on MR imaging and five $(5 \%)$ had further non-structural abnormalities. Of the 131 children who underwent imaging, neurodevelopmental assessment, sensory organ assessment or all of these tests, 19 (14\%) were found to have severe neurodevelopmental delay, sensory organ dysfunction or both.
N Engl J Med 2018; 379:2377-2379

\section{HOW'S YOUR FATHER?}

Extraordinary claims need extraordinary evidence. Researchers used high-depth whole mitochondrial DNA sequencing analysis (repeated in two independent laboratories), to investigate mitochondrial disease in three families. They identified paternally transmitted mtDNA variants and conclude that biparental mtDNA transmission is possible. Considerable doubt has been cast on these results-but if this was extremely rare, but true under certain circumstanceswhat next for mitochondrial donation and 'three parent babies'? The authors do conclude that paternal transmission events seem to have left no detectable mark on the historical human genetic record. Proc Natl Acad Sci U S A. 2018 (Epub ahead of print)

Funding The authors have not declared a specific grant for this research from any funding agency in the public, commercial or not-for-profit sectors.

Competing interests None declared.

Patient consent Not required.

Provenance and peer

review Commissioned; internally peer reviewed. 